\title{
Raman spectroscopy and microwave dielectric properties of Sn substituted $\mathrm{SrLa}_{4} \mathrm{Ti}_{5} \mathrm{O}_{17}$ ceramics
}

\author{
Abdul Manan $^{1 *}$, Atta Ullah ${ }^{2}$, Arbab Safeer Ahmad $^{1}$ \\ ${ }^{1}$ Department of Physics, University of Science and Technology Bannu, 28100, KPK, Pakistan \\ ${ }^{2}$ School of Materials Science and Engineering, Wuhan University of Technology, Wuhan, 430070, China \\ ${ }^{3}$ Department of Physics, Islamia College Peshawar, 25120 Peshawar, Pakistan
}

$\mathrm{SrLa}_{4} \mathrm{Ti}_{5-\mathrm{x}} \mathrm{Sn}_{\mathrm{x}} \mathrm{O}_{17}(0 \leqslant \mathrm{x} \leqslant 2)$ ceramics were fabricated through solid state ceramic route and their microwave dielectric properties were investigated in an attempt to tune their temperature coefficient of resonant frequency $\left(\tau_{\mathrm{f}}\right)$ to zero. The compositions were sintered to single phase $\mathrm{SrLa}_{4} \mathrm{Ti}_{5} \mathrm{O}_{17}$ and $\mathrm{SrLa}_{4} \mathrm{Ti}_{4.5} \mathrm{Sn}_{0.5} \mathrm{O}_{17}$ ceramics at $\mathrm{x}=0$ and $\mathrm{x}=0.5$, and

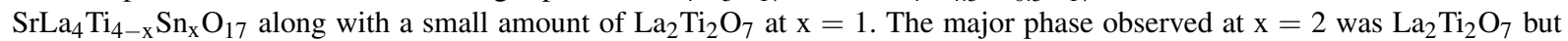
along with $\mathrm{SrLa}_{4} \mathrm{Ti}_{4} \mathrm{SnO}_{17}$ and $\mathrm{SrLa}_{4} \mathrm{Ti}_{4} \mathrm{O}_{15}$ as the secondary phases. $\tau_{\mathrm{f}}$ decreased from 117 to $23.0 \mathrm{ppm} /{ }^{\circ} \mathrm{C}$ but at the cost of dielectric constant $\left(\varepsilon_{\mathrm{r}}\right)$ and quality factor multiplied by resonant frequency $\left(\mathrm{Q}_{\mathrm{u}} \mathrm{f}_{\mathrm{o}}\right)$ which decreased from 65 to 33.6 and 11150 to $4191 \mathrm{GHz}$, respectively. The optimum microwave dielectric properties, i.e. $\tau_{\mathrm{f}}=38.6 \mathrm{ppm} /{ }^{\circ} \mathrm{C}, \varepsilon_{\mathrm{r}}=45.5$ and $\mathrm{Q}_{u} \mathrm{f}_{\mathrm{o}}=7919 \mathrm{GHz}$, correspond to the $\mathrm{SrLa}_{4} \mathrm{Ti}_{5-\mathrm{x}} \mathrm{Sn}_{\mathrm{x}} \mathrm{O}_{17}$ composition with $\mathrm{x}=1$.

Keywords: ceramics; microwave properties; Raman spectroscopy; SEM

(C) Wroclaw University of Technology.

\section{Introduction}

Lead free dielectric oxide ceramics with high electric permittivity $\left(\varepsilon_{\mathrm{r}}\right)$, high unloaded quality factor $\left(Q_{u}\right)$ and a near zero temperature coefficient of resonant frequency $\left(\tau_{\mathrm{f}}\right)$ are critical elements in the components, such as resonators, oscillators and filters for wireless communication. For commercial applications, any material used as a dielectric resonator must have $\varepsilon_{\mathrm{r}}>24$, $\mathrm{Q}_{\mathrm{u}} \mathrm{f}_{\mathrm{o}}>30,000 \mathrm{GHz}$ and $\left|\tau_{\mathrm{f}}\right| \leqslant 3 \mathrm{ppm} /{ }^{\circ} \mathrm{C}$ [1]. For certain applications, such as antennas, the requirements for low $\tau_{f}$ and high $\mathrm{Q}_{\mathrm{u}} \mathrm{f}_{\mathrm{o}}$ are flexible but $\varepsilon_{\mathrm{r}}$ is generally required to be as high as possible to miniaturize the device so that it might be incorporated into a handset [2]. Recently, layered perovskites with a general formula $\mathrm{A}_{n} \mathrm{~B}_{n} \mathrm{O}_{3 n+2}$ (where $\mathrm{A}$ and $\mathrm{B}$ are cations) have received much attention due to their high dielectric performance and applications in patch antennas. Jawahar et al. [2] reported $\mathrm{CaLa}_{4} \mathrm{Ti}_{5} \mathrm{O}_{17}$ with $\varepsilon_{r}=53$,

*E-mail: drmanan82@yahoo.com $\tau_{\mathrm{f}}=-20 \mathrm{ppm} /{ }^{\circ} \mathrm{C}$ and $\mathrm{Q}_{u} \mathrm{f}_{o}=17359 \mathrm{GHz}$ that was sintered at $1625{ }^{\circ} \mathrm{C}$. The microwave dielectric properties of $\mathrm{CaLa}_{4} \mathrm{Ti}_{5} \mathrm{O}_{17}$ ceramics were improved by substituting $\mathrm{Ca}^{2+}$ ions with $\mathrm{Zn}^{2+}$ ions [4]. $\varepsilon_{r}=57, \mathrm{Q}_{\mathrm{u}} \mathrm{f}_{\mathrm{o}}=15,000 \mathrm{GHz}$, and $\tau_{\mathrm{f}}=-8.16 \mathrm{ppm} /{ }^{\circ} \mathrm{C}$ were obtained for $\mathrm{Ca}_{0.99} \mathrm{Zn}_{0.01} \mathrm{La}_{4} \mathrm{Ti}_{5} \mathrm{O}_{17}$ ceramics with 0.5 wt. $\%$ $\mathrm{CuO}$ additive that were sintered at $1450{ }^{\circ} \mathrm{C}$ for $4 \mathrm{~h}$ [5]. On the other hand, $\mathrm{SrLa}_{4} \mathrm{Ti}_{5} \mathrm{O}_{17}$ was reported to have $\varepsilon_{\mathrm{r}}=61, \mathrm{Q}_{u} \mathrm{f}_{o}=9969 \mathrm{GHz}$ and $\tau_{\mathrm{f}}=117 \mathrm{ppm} /{ }^{\circ} \mathrm{C}$ [3]. The high positive $\tau_{\mathrm{f}}$ precluded its use as dielectrically loaded antenna. In previous studies, $\mathrm{Sm}$ and $\mathrm{Nd}$ substitution for $\mathrm{La}$ in $\mathrm{SrLa}_{4} \mathrm{Ti}_{5} \mathrm{O}_{17}$ resulted in $\tau_{\mathrm{f}} \sim 0 \mathrm{ppm} /{ }^{\circ} \mathrm{C}$ but at a cost of a decrease in $\mathrm{Q}_{u} \mathrm{f}_{o}$ to $3000 \mathrm{GHz}$ and $6000 \mathrm{GHz}$, respectively [6, 7]. The substitution of $\mathrm{Sn}^{4+}$ for $\mathrm{Ti}^{4+}$ has been reported to lower $\tau_{\mathrm{f}}$ of some compounds, for example, $\mathrm{Ba}_{4} \mathrm{LaMNb}_{3} \mathrm{O}_{15}$ $(\mathrm{M}=\mathrm{Ti}, \mathrm{Sn})[8,9]$ without any significant effect on the $\mathrm{Q}_{\mathrm{u}} \mathrm{f}_{\mathrm{o}}$; therefore, in the present study, the effects of $\mathrm{Sn}^{4+}$ substitution for $\mathrm{Ti}^{4+}$ on the phase, microstructure and microwave dielectric properties of $\mathrm{SrLa}_{4} \mathrm{Ti}_{5-\mathrm{x}} \mathrm{Sn}_{\mathrm{x}} \mathrm{O}_{17}(0 \leqslant \mathrm{x} \leqslant 2)$ ceramics were 
investigated in an attempt to lower $\tau_{\mathrm{f}}$ of the resulting compounds.

\section{Experimental}

$\mathrm{SrLa}_{4} \mathrm{Ti}_{5-\mathrm{x}} \mathrm{Sn}_{\mathrm{x}} \mathrm{O}_{17}(0 \leqslant \mathrm{x} \leqslant 2)$ batch compositions were prepared by weighing the required amounts of $\mathrm{SrCO}_{3}$ (Aldrich, 99+ \%), $\mathrm{La}_{2} \mathrm{O}_{3}$ (Aldrich, $99.95 \%$ ), $\mathrm{TiO}_{2}$ (Aldrich, anatase, 99+ \%) and $\mathrm{SnO}_{2}$ (Aldrich, $99.95 \%$ ). The mixed batches were ball milled for $24 \mathrm{~h}$ in polyethylene disposable mill-jars using Y-toughened $\mathrm{ZrO}_{2}$ balls as grinding media and isopropanol as lubricant to make freely flowing slurries. The resulting slurries were dried in and oven kept at $95{ }^{\circ} \mathrm{C}$ for about $24 \mathrm{~h}$ and then calcined at $1250{ }^{\circ} \mathrm{C}$ to $1300{ }^{\circ} \mathrm{C}$ for $6 \mathrm{~h}$ at a heating/cooling rate of $5^{\circ} \mathrm{C} / \mathrm{min}$. The calcined powders were finely ground in an agate pestle and mortar for $45 \mathrm{~min}$ and then pressed into 4 to $5 \mathrm{~mm}$ high and $10 \mathrm{~mm}$ diameter pellets in a steel die at $80 \mathrm{MPa}$. The pellets were sintered at 1450 to $1650{ }^{\circ} \mathrm{C}$ for $4 \mathrm{~h}$ at a heating/cooling rate of $5{ }^{\circ} \mathrm{C} / \mathrm{min}$. Densities of the sintered pellets were measured using Archimedes method. Phase analysis of the sintered samples was carried out using a Philips X-ray diffractometer (XRD) with $\mathrm{CuK} \alpha$ radiation $(\lambda=1.5406 \AA)$ operating at $30 \mathrm{kV}$ and $40 \mathrm{~mA}$ at $1 \% \mathrm{~min}$ in $2 \theta=10$ to $70^{\circ}$ with a step size of $0.02^{\circ}$. A Renishaw's inVia Raman microscope was used for Raman measurements. The microwave dielectric properties were measured using a R3767CH Agilent network analyzer by placing the cylindrical pellets on a low loss quartz single crystal at the center of an Au-coated brass cavity. $\tau_{f}$ was measured by measuring the temperature variation of $\mathrm{TE}_{01 \delta}$ resonance mode in the temperature range of 20 to $80{ }^{\circ} \mathrm{C}$.

\section{Results and discussion}

Fig. 1 shows the XRD patterns recorded at room temperature for optimally sintered $\mathrm{SrLa}_{4} \mathrm{Ti}_{5-\mathrm{x}} \mathrm{Sn}_{\mathrm{x}} \mathrm{O}_{17}(0 \leqslant \mathrm{x} \leqslant 2)$ ceramics. The patterns of the compositions with $\mathrm{x}=0,0.5$ and 1 were identical and matched with the one reported for $\mathrm{SrLa}_{4} \mathrm{Ti}_{5} \mathrm{O}_{17}$ (PDF\# 57-00940) but with an appropriate shift in the peaks positions towards lower angles for the samples with $\mathrm{x}=0.5$ and 1 due to the presence of relatively larger $\mathrm{Sn}$ ions at the B-site of the perovskite unit cell. This indicated the formation of some $\mathrm{SrLa}_{4} \mathrm{Ti}_{4.5} \mathrm{Sn}_{0.5} \mathrm{O}_{17}$ and $\mathrm{SrLa}_{4} \mathrm{Ti}_{4} \mathrm{SnO}_{17}$ compounds containing isostructural phases with $\mathrm{SrLa}_{4} \mathrm{Ti}_{5} \mathrm{O}_{17}$ at $\mathrm{x}=0.5$ and 1 . The presence of a few low intensity XRD peaks indicated the beginning of the formation of a secondary $\mathrm{La}_{2} \mathrm{Ti}_{2} \mathrm{O}_{7}$ (PDF\# 70-1690) phase at $\mathrm{x}=1$. At $\mathrm{x}=2, \mathrm{La}_{2} \mathrm{Ti}_{2} \mathrm{O}_{7}$ (PDF\# 70-1690) was observed as the major phase but along with $\mathrm{SrLa}_{4} \mathrm{Ti}_{4} \mathrm{SnO}_{17}$ and $\mathrm{SrLa}_{4} \mathrm{Ti}_{4} \mathrm{O}_{15}$ (PDF\# 49-0254) as minor phases. The observed increase in the intensity of the XRD peaks due to $\mathrm{La}_{2} \mathrm{Ti}_{2} \mathrm{O}_{7}$ indicated an increase in their amount with increasing $\mathrm{x}$.

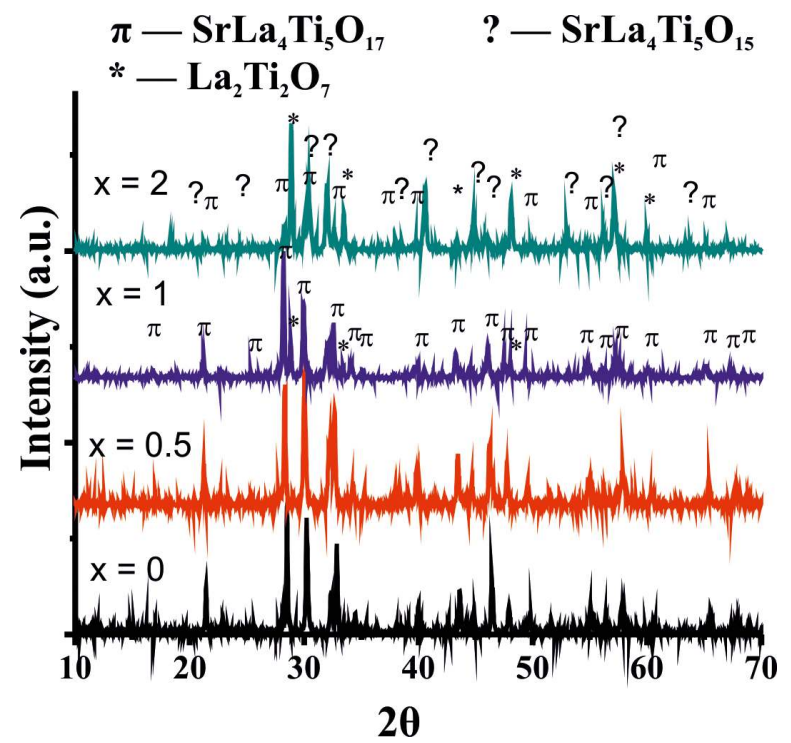

Fig. 1. XRD patterns of $\mathrm{SrLa}_{4} \mathrm{Ti}_{5-\mathrm{x}} \mathrm{Sn}_{\mathrm{x}} \mathrm{O}_{17}$ $(0 \leqslant x \leqslant 2)$ ceramics, showing the formation of $\mathrm{SrLa}_{4} \mathrm{Ti}_{5} \mathrm{O}_{17}, \mathrm{SrLa}_{4} \mathrm{Ti}_{4.5} \mathrm{Sn}_{0.5} \mathrm{O}_{17}$ at $\mathrm{x}=0$ and $0.5, \mathrm{SrLa}_{4} \mathrm{Ti}_{4} \mathrm{Sn}_{1} \mathrm{O}_{17}$ along with $\mathrm{La}_{2} \mathrm{Ti}_{2} \mathrm{O}_{7}$ at $\mathrm{x}=1$ and $\mathrm{La}_{2} \mathrm{Ti}_{2} \mathrm{O}_{7}$ and $\mathrm{SrLa}_{4} \mathrm{Ti}_{4} \mathrm{O}_{15}$ along with a few diminishing peaks due to $\mathrm{SrLa}_{4} \mathrm{Ti}_{4} \mathrm{SnO}_{17}$ at $\mathrm{x}=2$.

The secondary electron images (SEIs) of thermally etched and gold-coated surfaces of $\mathrm{SrLa}_{4} \mathrm{Ti}_{5-\mathrm{x}} \mathrm{Sn}_{\mathrm{x}} \mathrm{O}_{17}(0 \leqslant \mathrm{x} \leqslant 2)$ ceramics sintered at their optimum sintering temperatures are shown in Fig. 2. The microstructure of the compositions with $\mathrm{x}=0$, and 0.5 comprised of elongated grains of the size ranging from $1 \times 1 \mu \mathrm{m}^{2}$ to $5 \times 7 \mu \mathrm{m}^{2}$ and $1 \times 3 \mu \mathrm{m}^{2}$ to $5 \times 20 \mu \mathrm{m}^{2}$ (Fig. $2 \mathrm{a}$ 
and Fig. 2b). Semi-quantitative SEM EDS (Table 1) of the grains labeled as "A" and "B" indicated that the composition of these grains was close to $\mathrm{SrLa}_{4} \mathrm{Ti}_{5} \mathrm{O}_{17}$ and $\mathrm{SrLa}_{4} \mathrm{Ti}_{4.5} \mathrm{Sn}_{0.5} \mathrm{O}_{17}$, respectively. Generally, the microstructure of the composition with $\mathrm{x}=1$ also comprised of elongated rod and plate-shaped grains labeled as "c" (Fig. 2c), where the molar elemental composition of these grains was close to $\mathrm{SrLa}_{4} \mathrm{Ti}_{4} \mathrm{SnO}_{17}$ (Table 1). The microstructure of the composition with $\mathrm{x}=2 \mathrm{com}$ prised of micro-regions including cubical grains labeled as "D" (Fig. 2d). Semi-quantitative EDS (Table 1) indicated that the composition of these grains was close to $\mathrm{La}_{2} \mathrm{Ti}_{2} \mathrm{O}_{7}$ phase as the EDS detected little $\mathrm{Sr}$ or $\mathrm{Sn}$ in these grains. This suggested the presence of grains due to $\mathrm{La}_{2} \mathrm{Ti}_{2} \mathrm{O}_{7}$ phase as observed by XRD of the same composition. The observed variation in the composition of the grains (Table 1) combined with the morphological change from rod-shaped grains to cubical grains with an increase in $\mathrm{Sn}$ content indicated the formation of secondary phases.
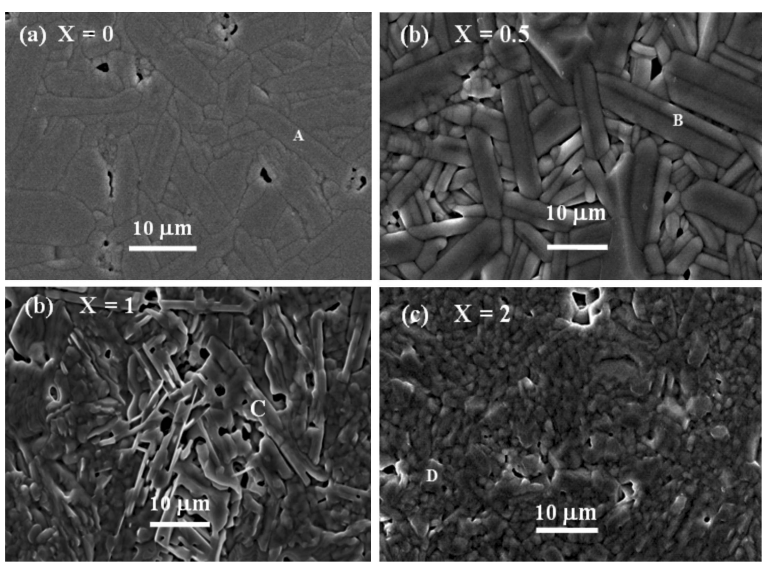

Fig. 2. SEIs recorded from thermally etched, goldcoated sintered $\mathrm{SrLa}_{4} \mathrm{Ti}_{5-\mathrm{x}} \mathrm{Sn}_{\mathrm{x}} \mathrm{O}_{17}$ compositions showing (a) elongated grains at $\mathrm{x}=0$, (b) elongated grains at $x=0.5$, (c) elongated grains at $\mathrm{x}=1$, (d) cuboidal shaped grains at $\mathrm{x}=2$.

The change from one compound to another with compositions can also be proved by Raman spectra analysis.

Raman spectroscopy is considered to be an ideal tool for probing the degree of cation ordering, also suitable to study dynamic changes in a structure. Fig. 3 illustrates the Raman spectra of $\mathrm{SrLa}_{4} \mathrm{Ti}_{5-\mathrm{x}} \mathrm{Sn}_{\mathrm{x}} \mathrm{O}_{17}(0 \leqslant \mathrm{x} \leqslant 2)$ ceramics. The spectra are very similar to those of the related compounds in the $\mathrm{Ca}_{1-\mathrm{x}} \mathrm{Zn}_{\mathrm{x}} \mathrm{La}_{4} \mathrm{Ti}_{5} \mathrm{O}_{17}$ series [4]. Generally, corner shared and edge-shared octahedra are predominant in $(\mathrm{Nb}, \mathrm{Ti})-\mathrm{O}$ polyhedra. In the corner-shared octahedra, the symmetric stretching vibrations are observed in the 750 to $850 \mathrm{~cm}^{-1}$ region [10].

Table 1. Elemental composition (in moles) calculated from semi-quantitative EDS data of the grains labelled in Fig. 2.

\begin{tabular}{ccccc}
\hline Grain & Sr & La & Ti & Sn \\
\hline \hline A & 1 & 4.12 & 4.26 & 0 \\
B & 1 & 4.10 & 4.20 & 0.6 \\
C & 2.95 & 10.17 & 9.36 & 1 \\
D & 1.35 & 13.93 & 15.09 & 1 \\
\hline
\end{tabular}

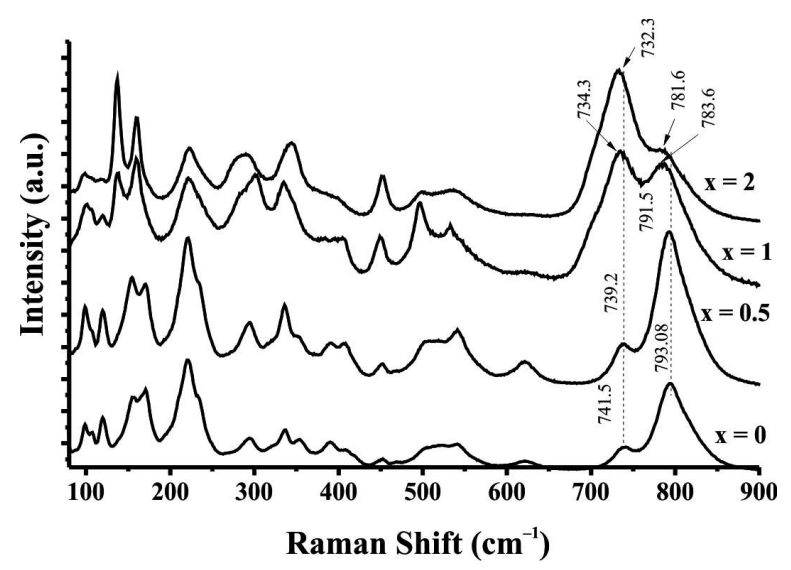

Fig. 3. Raman spectra recorded at room temperature for $\mathrm{SrLa}_{4} \mathrm{Ti}_{5-\mathrm{x}} \mathrm{Sn}_{\mathrm{x}} \mathrm{O}_{17}(0 \leqslant \mathrm{x} \leqslant 2)$ compositions.

In the present study, the highest frequency $\mathrm{A}_{1 \mathrm{~g}}$ mode at $793.08 \mathrm{~cm}^{-1}$ for $\mathrm{x}=0$ corresponds to the symmetric metal-oxygen stretching vibrations of the $\mathrm{BO}_{6}$ octahedra, but it is shifted towards lower frequency of $781 \mathrm{~cm}^{-1}$ as the value of $\mathrm{x}$ increased from 0 to 2 , along with a decrease in its intensity. This is due to the incorporation of bigger cation of $\mathrm{Sn}^{+4}(0.69 \AA)$ in place of smaller cation of $\mathrm{Ti}^{4+}(0.605 \AA)$ [11] which induced a decrease in the force constant or the stiffness of the oxygen octahedral cage as a result of the covalent 
character of the central $\mathrm{TiO}_{6}$ octahedra [4]. The vibrational modes in the 750 to $850 \mathrm{~cm}^{-1}$ region, supported the existence of the corner shared octahedra in the $\mathrm{SrLa}_{4} \mathrm{Ti}_{5-\mathrm{x}} \mathrm{Sn}_{\mathrm{x}} \mathrm{O}_{17}$ series of compounds. The XRD revealed $\mathrm{La}_{2} \mathrm{Ti}_{2} \mathrm{O}_{7}$ as the major phase and $\mathrm{SrLa}_{4} \mathrm{Ti}_{4} \mathrm{O}_{15}$ as the secondary phase with the increase in peak intensities. Since $\mathrm{La}_{2} \mathrm{Ti}_{2} \mathrm{O}_{7}$ has only one cation at the $\mathrm{B}$ site, no $\mathrm{A}_{1 \mathrm{~g}}$ Raman mode was active. The new Raman active mode band with increased intensity that appeared at $734 \mathrm{~cm}^{-1}$, suppressing the $\mathrm{A}_{1 \mathrm{~g}}$ mode at $781 \mathrm{~cm}^{-1}$ for $\mathrm{x} \geqslant 1$, could be attributed to the $\mathrm{A}_{1 \mathrm{~g}}$ mode of $\mathrm{BO}_{6}$ octahedra in $\mathrm{SrLa}_{4} \mathrm{Ti}_{4} \mathrm{O}_{15}$ ceramics that developed as a secondary phase along with $\mathrm{La}_{2} \mathrm{Ti}_{2} \mathrm{O}_{7}$ as a major phase. The weak band observed at 605 to $620 \mathrm{~cm}^{-1}$ range can be assigned to the B-O symmetric stretching vibration $[12,13]$. The broad bands at 450 to $570 \mathrm{~cm}^{-1}$ can be represented as symmetric breathing of the $\mathrm{BO}_{6}$ octahedra [14]. The $\mathrm{E}_{\mathrm{g}}$ modes in the range of 200 to $400 \mathrm{~cm}^{-1}$ have been assigned to $\mathrm{O}-\mathrm{B}-\mathrm{O}$ bending mode [12]. The modes in the range of 470 to $490 \mathrm{~cm}^{-1}$ were described as B-O torsional modes [15]. The modes at 314 and $464 \mathrm{~cm}^{-1}$ can be attributed to the rotating and tilting of the $\mathrm{BO}_{6}$ octahedron [15]. The intensity of the bands around 250 to $350 \mathrm{~cm}^{-1}$ increased with an increase in the $\mathrm{x}$ value and also shifted towards higher frequencies.

The modes below $250 \mathrm{~cm}^{-1}$ can be assigned to lattice vibrations of the A-site cations.

The microwave dielectric properties of $\mathrm{SrLa}_{4} \mathrm{Ti}_{5-\mathrm{x}} \mathrm{Sn}_{\mathrm{x}} \mathrm{O}_{17}(0 \leqslant \mathrm{x} \leqslant 2)$ ceramics sintered at their optimum sintering temperatures are shown in Fig. 4 and Fig. 5 and are also compared in Table 2. $\varepsilon_{\mathrm{r}}, \tau_{\mathrm{f}}$ and $\mathrm{Q}_{\mathrm{u}} \mathrm{f}_{\mathrm{o}}$ were observed to decrease from 65.0 to $33.8,118 \mathrm{ppm} /{ }^{\circ} \mathrm{C}$ to $21.0 \mathrm{ppm} /{ }^{\circ} \mathrm{C}$ and $11150 \mathrm{GHz}$ to $4191 \mathrm{GHz}$ with an increase in $\mathrm{Sn}^{4+}$ content from 0 to 2 , respectively. It has been reported that the substitution of $\mathrm{Sn}^{4+}$ for $\mathrm{Ti}^{4+}$ caused a decrease in $\varepsilon_{\mathrm{r}}$, hence, $\tau_{\mathrm{f}}$ in other compounds [9]. Therefore, the observed decrease in $\varepsilon_{\mathrm{r}}$ (Fig. 4) could be attributed to the less ionic dielectric polarizability $\left(2.83 \AA^{3}\right)$ of $\mathrm{Sn}^{4+}$ in comparison to $\left(2.93 \AA^{3}\right)$ of $\mathrm{Ti}^{4+}$ [16]. However, for $1 \leqslant \mathrm{x} \leqslant 2$, the decrease in $\varepsilon_{\mathrm{r}}$ could be attributed to the formation of the secondary phase of $\mathrm{La}_{2} \mathrm{Ti}_{2} \mathrm{O}_{7}$ with $\varepsilon_{\mathrm{r}}=22$ [4]. The observed decrease in $\mathrm{Q}_{\mathrm{u}} \mathrm{f}_{\mathrm{o}}$ (Fig. 5) upon increasing Sn content from 1 to 2 may be due to the formation of secondary phases, whose interface causes additional dielectric loss [10]. $\tau_{\mathrm{f}}$ decreased from 117 to $23.0 \mathrm{ppm} /{ }^{\circ} \mathrm{C}$ (Fig. 4) with the increase in $\mathrm{x}$ from 0 to 2 but at the cost of $\varepsilon_{\mathrm{r}}$ and $\mathrm{Q}_{\mathrm{u}} \mathrm{f}_{\mathrm{o}}$ which decreased from 65 to 33.6 and 11150 to $4339 \mathrm{GHz}$, respectively, due to the formation of secondary phases which made higher concentrations of Sn unfavorable. Thus, the optimum microwave dielectric properties $\left(\tau_{\mathrm{f}}=\right.$ $39 \mathrm{ppm} /{ }^{\circ} \mathrm{C}, \varepsilon_{\mathrm{r}}=46$ and $\mathrm{Q}_{\mathrm{u}} \mathrm{f}_{\mathrm{o}}=7900 \mathrm{GHz}$ ), corresponded to the $\mathrm{SrLa}_{4} \mathrm{Ti}_{5-\mathrm{x}} \mathrm{Sn}_{\mathrm{x}} \mathrm{O}_{17}$ composition with $\mathrm{x}=1$ with minimum $\mathrm{Sn}$ content, hence, the secondary phases.

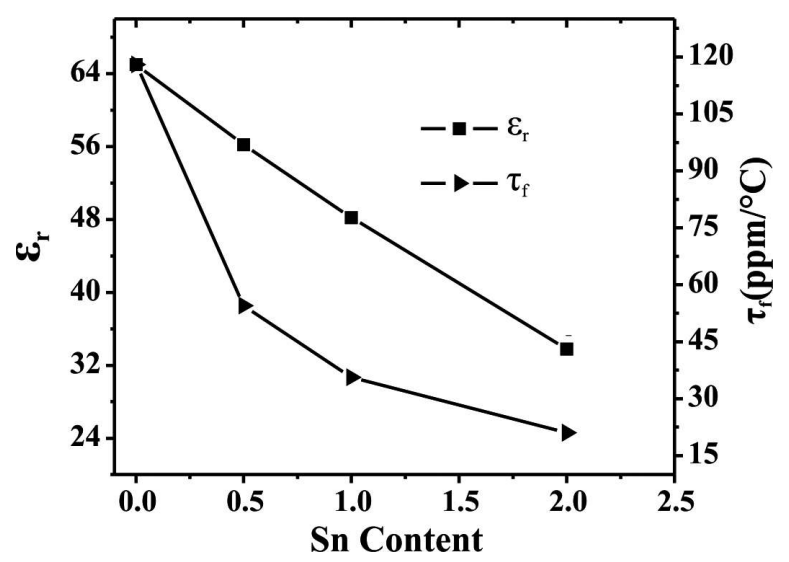

Fig. 4. Variation in $\varepsilon_{\mathrm{r}}$ and $\tau_{\mathrm{f}}$ versus $\mathrm{Sn}^{4+}$ content (x) for $\mathrm{SrLa}_{4} \mathrm{Ti}_{5-\mathrm{x}} \mathrm{Sn}_{\mathrm{x}} \mathrm{O}_{17}(0 \leqslant \mathrm{x} \leqslant 2)$ compositions sintered at their optimum sintering temperatures.

\section{Conclusions}

$\mathrm{SrLa}_{4} \mathrm{Ti}_{5-\mathrm{x}} \mathrm{Sn}_{\mathrm{x}} \mathrm{O}_{17}$ compositions crystallize into single phase ceramics at $\mathrm{x}=0$, and $\mathrm{x}=0.5$, while the formation of a small amount of second phase begins at $x=1$. The substitution of $\mathrm{Sn}$ for Ti causes a substantial decrease in $\tau_{f}$ but at a cost of $\varepsilon_{\mathrm{r}}$ and $\mathrm{Q}_{\mathrm{u}} \mathrm{f}_{\mathrm{o}}$ due to the second phase formation, which makes higher concentration of $\mathrm{Sn}$ unfavorable. The optimum microwave dielectric properties, i.e. $\tau_{\mathrm{f}}=35.6 \mathrm{ppm} /{ }^{\circ} \mathrm{C}$, 
Table 2. Preparation conditions, apparent densities and microwave dielectric properties of $\mathrm{SrLa}_{4} \mathrm{Ti}_{5-\mathrm{x}} \mathrm{Sn}_{\mathrm{x}} \mathrm{O}_{17}$ $(0 \leqslant x \leqslant 2)$.

\begin{tabular}{ccccccc}
\hline $\mathrm{x}$ & $\mathrm{CT}\left[{ }^{\circ} \mathrm{C}\right]$ & $\mathrm{ST}\left[{ }^{\circ} \mathrm{C}\right]$ & $\rho_{\exp }\left[\mathrm{g} / \mathrm{cm}^{3}\right]$ & $\varepsilon_{\mathrm{r}}$ & $\mathrm{Q}_{\mathrm{u}} \mathrm{f}_{\mathrm{o}}[\mathrm{GHz}]$ & $\tau_{\mathrm{f}}\left[\mathrm{ppm} /{ }^{\circ} \mathrm{C}\right]$ \\
\hline \hline 0 & $1250 / 6 \mathrm{~h}$ & $1500 / 4 \mathrm{~h}$ & 5.41 & 65.0 & 11150 & +118 \\
0.5 & $1300 / 6 \mathrm{~h}$ & $1600 / 4 \mathrm{~h}$ & 5.63 & 56.2 & 9450 & +54.5 \\
1 & $1300 / 6 \mathrm{~h}$ & $1625 / 4 \mathrm{~h}$ & 5.60 & 48.2 & 8278 & +35.6 \\
2 & $1300 / 6 \mathrm{~h}$ & $1625 / 4 \mathrm{~h}$ & 5.75 & 33.8 & 4345 & +21.0 \\
\hline \multicolumn{7}{c}{$\mathrm{CT}=$ Calcination temperature, ST $=$ Sintering temperature, $\rho_{\mathrm{ap}}=$ Apparent density }
\end{tabular}

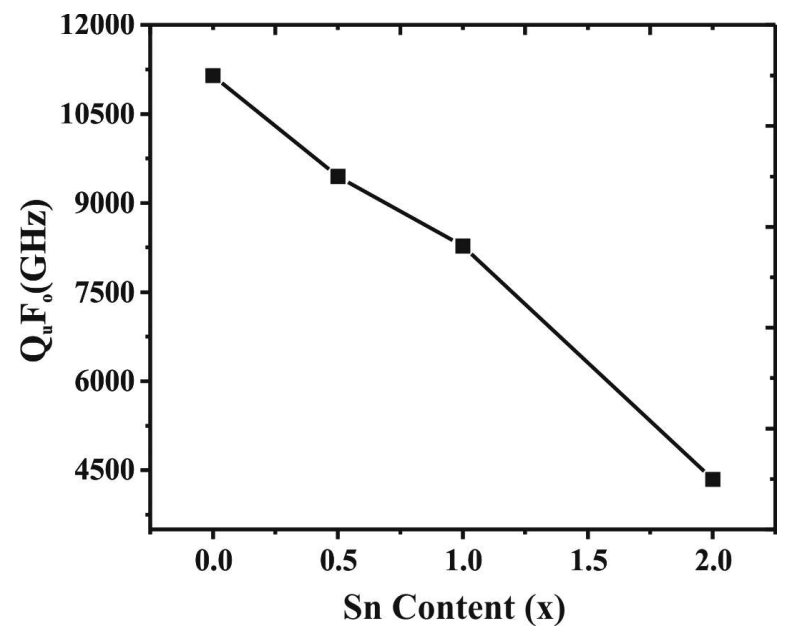

Fig. 5. Variation in $\mathrm{Q}_{\mathrm{u}} \mathrm{f}_{\mathrm{o}}$ versus $\mathrm{Sn}^{4+}$ content (x) for $\mathrm{SrLa}_{4} \mathrm{Ti}_{5-\mathrm{x}} \mathrm{Sn}_{\mathrm{x}} \mathrm{O}_{17}(0 \leqslant \mathrm{x} \leqslant 2)$ compositions sintered at their optimum sintering temperatures.

$\varepsilon_{\mathrm{r}}=48.6$ and $\mathrm{Q}_{u} \mathrm{f}_{o}=8278 \mathrm{GHz}$, correspond to the $\mathrm{SrLa}_{4} \mathrm{Ti}_{5-\mathrm{x}} \mathrm{Sn}_{\mathrm{x}} \mathrm{O}_{17}$ composition with $\mathrm{x}=1$.

\section{Acknowledgements}

The authors acknowledge the financial support of the Higher Education Commission of Pakistan under the International Research Support Initiative Program (IRSIP) Scheme and the Electroceramics group at the department of Materials Science and Engineering University of Sheffield UK.

\section{References}

[1] Reaney I.M., Idles D., J. Am. Ceram. Soc., 89 (2006), 2068

[2] Jawahar I.N., Santha N.I., Sebastian M.T., MoHANAN P., J. Mater. Res., 17 (2002), 3084.

[3] Iqbal Y., Manan A., Reaney I.M., Mater. Res. Bull., 46 (2011), 1092.

[4] FEI Z.Y., J. Am. Ceram. Soc., 89 (2006), 3421.

[5] Chen Y.C., Tsai J.M., Jpn. J. Appl. Phys., 47 (2008), 7959.

[6] Manan A., IQbal Y., J. Mater. Sci. Mater. Electron., 22 (2011), 1848.

[7] Manan A., IQbal Y., Mater. Res. Bull., 47 (2012), 883.

[8] FAng L., Mater. Res. Bull., 39 (2004), 1649.

[9] Manan A., Hussain I., Int. J. Mod. Phys. B, 28 (2014), 1450092.

[10] Ratheesh R., Sreemoolanadhan H., Sebastian M.T., J. Solid State. Chem., 131 (1997), 2.

[11] Shannon R.D., Acta. Crystallogr. A, 32 (751) (1976), 751.

[12] Zheng H., J. Mater. Res., 19 (2004), 488.

[13] Levin I., J. Solid State. Chem., 156 (2001), 122.

[14] Hirata T., Ishioka K., Kitajima M., J. Solid State. Chem., 124 (1996), 353.

[15] HaO H., Appl. Phys. A, 85 (2006), 69.

[16] Shannon R.D., J. Appl. Phys., 73 (1993), 348.

Received 2014-08-24 Accepted 2015-11-11 